\title{
The treatment of onychogryphosis of hand nails by total matricectomy and dorsal V-Y advancement flap
}

\author{
Kaan Gürbüz, MD (D) \\ Department of Orthopedics and Traumatology, Kayseri City Hospital, Kayseri, Turkey
}

Onychogryphosis is a trophic disorder of the nail plate, which occurs most commonly in the toenails and results in a ram's horn-shaped nail deformity. In clinical terms, it is characterized by marked thickening and convexity, increased consistency, and yellow-brownish discoloration of the affected nail plate. ${ }^{[1-4]}$ It may be congenital, idiopathic, or associated with poor self-care due to advancing age, homelessness, and senile dementia, severe single or repeated nail traumas resulting in suppuration or scarring of the nail bed, impaired peripheral circulation, inappropriate surgical interventions due to bacterial infections such as paronychia, and diseases such as psoriasis, ichthyosis, onychomycosis, syphilis, or pemphigus, etc. ${ }^{[2,5-7]}$

The main objective of palliative and surgical treatment modalities described for the treatment of onychogryphosis is to minimize the patient's complaints by avoiding excessive pressure on the nail bed applied by the thickened nail plate. ${ }^{[7]}$ In this study, we aimed to report the outcomes of dorsal V-Y advancement flap technique used for the reconstruction of surgical defects following total matricectomy performed for the onychogryphosis of hand nails. ${ }^{[8]}$

Received: July 16, 2019

Accepted: September 04, 2019

Published online: March 02, 2020

Correspondence: Kaan Gürbüz, MD. Kayseri Șehir Hastanesi, Ortopedi ve Travmatoloji Kliniği, 38080 Kocasinan, Kayseri, Türkiye.

E-mail: drkagangurbuz@gmail.com

Doi: 10.5606/ehc.2020.70611

Citation: Gürbüz K. The treatment of onychogryphosis of hand nails by total matricectomy and dorsal $V-Y$ advancement flap. Jt Dis Relat Surg 2020;31(1):39-42.

\section{ABSTRACT}

Objectives: This study aims to report the outcomes of dorsal $\mathrm{V}-\mathrm{Y}$ advancement flap technique used for the reconstruction of surgical defects following total matricectomy performed for the onychogryphosis of hand nails.

Patients and methods: A total of 18 consecutive patients (10 males, 8 females; mean age 38.4 years; range, 24 to 41 years) with 20 onychogryphotic hand nails who underwent total matricectomy and dorsal V-Y advancement flap technique were analyzed retrospectively between June 2015 and March 2018. The MannWhitney U test was used to compare the pre- and postoperative Quick Disability of the Arm, Shoulder, and Hand (Quick DASH) questionnaire scores while postoperative satisfaction rate was also evaluated.

Results: The mean follow-up period of the patients was 15.3 months. The etiology was finger trauma in eight and surgical complication of recurrent paronychia drainage in four cases, while the remaining six were idiopathic. The mean time to return to work was 5.2 weeks, and the mean pre- and postoperative Quick DASH scores were 0.97 and 3.45 , respectively, with a statistically significant difference. The postoperative satisfaction was rated as excellent in 16, good in one, and moderate in one case.

Conclusion: The dorsal V-Y advancement flap technique can be performed reliably due to its good soft tissue coverage, satisfactory cosmetic and functional outcomes, and allowing a short time to return to work.

Keywords: Matricectomy, nail, oncychogryphosis, V-Y advancement flap.

\section{PATIENTS AND METHODS}

Eighteen consecutive patients (10 males, 8 females; mean age 38.4 years; range, 24 to 41 years) with 20 onychogryphotic hand nails ( 2 right thumbs, 1 left thumb, 6 right and 6 left index fingers, 3 left middle fingers, 1 right fourth finger, and 1 left little finger), who underwent total matricectomy and dorsal V-Y advancement flap technique at Kayseri City Hospital between June 2015 and March 2018, were analyzed retrospectively regarding demographics and clinical data. At least six months after the surgery, the patients 
were asked to assess their postoperative satisfaction rate as excellent, good, moderate, or poor. Furthermore, the validated Turkish version of the Quick Disability of the Arm, Shoulder, and Hand (Quick DASH) questionnaire $^{[9]}$ was used preoperatively and after the sixth month of surgery to evaluate the functional outcomes by comparing pre- and postoperative scores. The study protocol was approved by the Kayseri City Hospital Ethics Committee (approval date, June 26, 2019; approval number, 2019/11). A written informed consent was obtained from each patient. The study was conducted in accordance with the principles of the Declaration of Helsinki.

All surgical procedures were performed under digital nerve blockade and strict sterile precautions. A pneumatic tourniquet or a flat Penrose drain (Galena Health Industry and Trading Corporation, Istanbul, Turkey) was applied throughout the surgery for obtaining hemostasis. By using a pair of forceps, the nail plate was totally avulsed by dissecting it from the nail folds and matrices. After excision of the germinal and sterile matrices and nail folds by the combined use of surgical excision and electrocautery, a dorsally located V-Y advancement flap, which was designed according to the length and width of the defect area, was dissected. The tip of the flap was located just proximal to the distal interphalangeal creases, and the base of the flap was located at the edge of the surgical defect. In all cases, Cleland's ligaments were divided and released in order to achieve a better flap advancement. By this maneuver, a 2-3 $\mathrm{mm}$ of flap advancement was achieved comfortably. In seven cases with a long nail bed, shortening of the distal phalanx was performed in order to achieve tension free and total closure of the defect area.

Following hemostasis and suture closure of the flap and donor site primarily, a light compressive

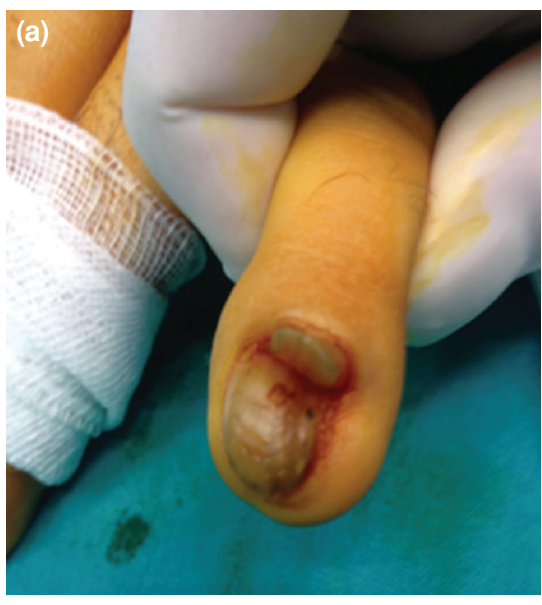

(c)
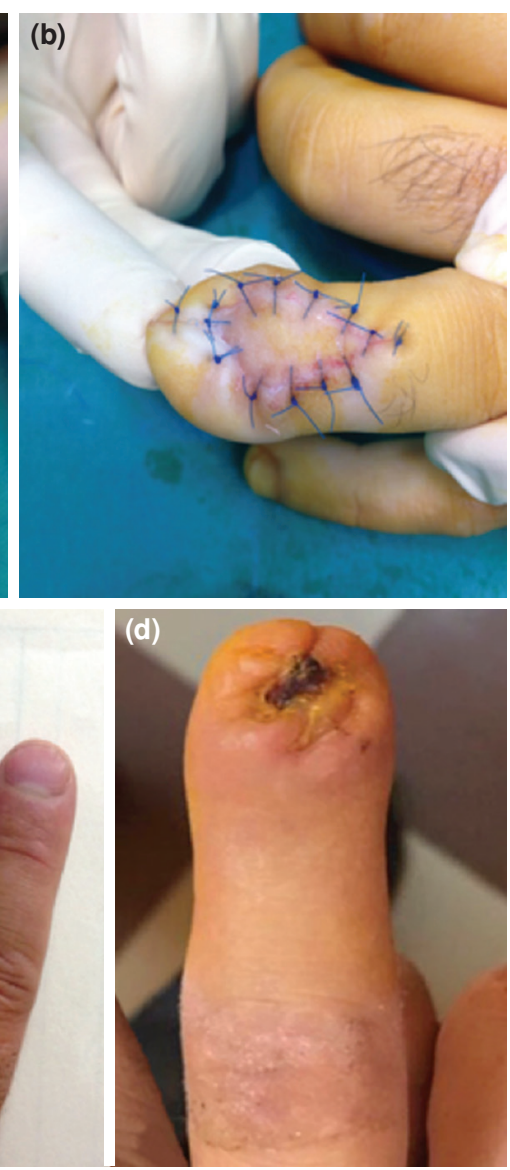

FIGURE 1. (a) Preoperative view of the left fourth finger with onychogryphosis deformity, (b) intraoperative view after shortening of $2 \mathrm{~mm}$ of distal phalanx and advancement of the V-Y flap, (c) early postoperative, and (d) postoperative second month view of the surgical field. 
dressing and splint positioning of the finger were applied. Postoperatively, the patients were generally discharged on the day of surgery with a regimen of prophylactic antibiotics and non-steroidal antiinflammatory drugs. Active range of movement was started after 7-10 days of finger splinting.

\section{Statistical analysis}

The PASW version 17.0 was used to analyze the data set (SPSS Inc., Chicago, IL, USA). The MannWhitney U test was used to compare the pre- and postoperative Quick DASH scores of the cases, and a $p$ value of less than 0.05 was considered as statistically significant.

\section{RESULTS}

The mean follow-up period of the patients was 15.3 months. The etiology was finger trauma in eight and surgical complication of recurrent paronychia drainage in four cases, while the remaining six were idiopathic. The primary complaints included repeated nail trauma during daily activities, pain, cosmetic deformity, and difficulty in wearing gloves and other functional problems when grasping or pinching.
No complications regarding wound healing process, flap survival, recurrence, or spicule development were observed during the follow-up period. The mean time to return to work was 5.2 weeks, and the mean pre- and postoperative Quick DASH scores were $1.0 \pm 1.6$ and $3.5 \pm 0.5$, respectively, with a statistically significant difference $(p<0.05)$. The postoperative satisfaction was rated as excellent in 16, good in one, and moderate in one case. Representative cases are shown in Figures 1 and 2.

\section{DISCUSSION}

There are various excisional or ablative matricectomy techniques described for the treatment of onychogryphotic nails by the carbon dioxide laser, phenolization, electrocautery or cold steel. ${ }^{[3,7,10-12]}$ Unlike the matricectomy techniques which result in total loss of the nail plate, ${ }^{[3,7,71,12]}$ Oka et al ${ }^{[10]}$ reported the successful outcomes of using an onychocutaneous free flap elevated from the big toe to reconstruct a novel nail apparatus. However, such a procedure requires considerable experience with microsurgical techniques and entails a rather lengthy operation with a possible risk of surgical failure.

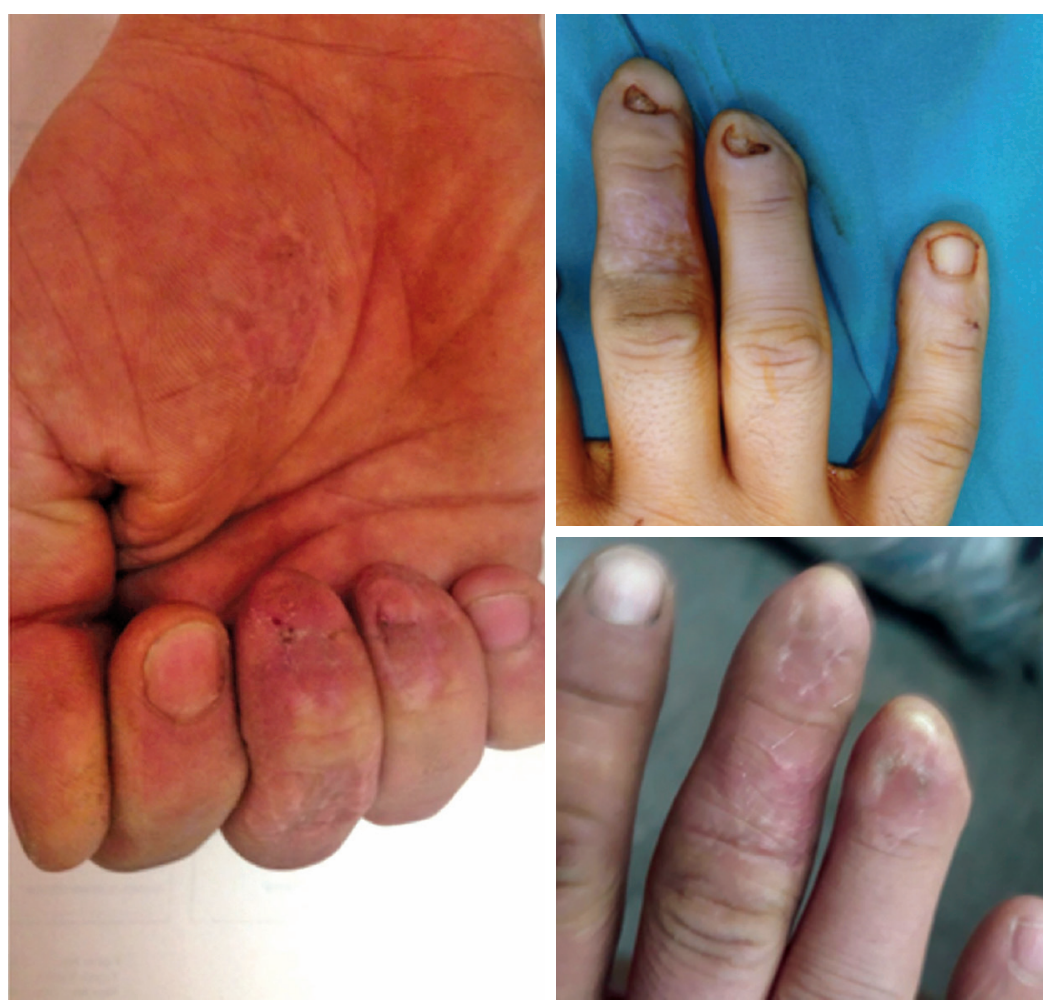

FIGURE 2. Preoperative and late postoerative views of the right middle and fourth fingers with trauma-related bone lose and onychogryphosis deformity. 
On the volar aspect of the distal phalanx, Atasoy's $\mathrm{V}-\mathrm{Y}$ advancement flap technique is a popular choice for reconstructing the distal pulp defects. ${ }^{[13]}$ Similar to Atasoy's technique, Yii et al. ${ }^{[14]}$ and Ozyigit et al. ${ }^{[15]}$ reported successful outcomes of using dorsal V-Y advancement flaps for reconstructing the defects of dorsal aspects of the hand fingers. Yii et al. ${ }^{[14]}$ specified that advancement of a V-Y flap located distally on the dorsum of the fingers can be a challenge due to less spare skin and insufficient subcutaneous tissue which makes the defects reconstructed by this technique smaller. For this reason, the authors divided bilateral Cleland's ligaments, ${ }^{[14]}$ which act as skin anchors maintaining the skin in a fixed relationship to the underlying architecture. ${ }^{[16]}$ However, in an earlier clinical series reported by Gürbüz et al., ${ }^{[17]}$ dorsal $\mathrm{V}-\mathrm{Y}$ advancement flap technique was used for the treatment of onychogryphotic toenails without the requirement of distal phalangeal shortening and releasing Clealand's ligaments. It was primarily due to the relatively thicker and more mobile subcutaneous tissue and thinner and shorter Clealand's ligaments of the toe, when compared to the hand fingers. ${ }^{[18]}$

As described by Yii et al. ${ }^{[14]}$ and as we experienced, the release of Cleland's ligaments on both sides resulted in facilitating the flap advancement with a decreased tension and retaining the length of the distal phalanx as much as possible. In cases with a long nail bed, which was unable to be covered due to the limited size and insufficient advancement of the flap, the distal phalanx was shortened, and it was not more than $2 \mathrm{~mm}$ in any case.

In this series, excisional or ablative matricectomy techniques were not preferred because of the long keratinization process of the nail bed, which was approximately six weeks, ${ }^{[19]}$ and its insufficient soft tissue coverage against traumas and infections.

The most important limitation of this study is the limited number of patients. In addition, the results obtained by the application of surgical technique by a single surgeon. Multicenter, prospective studies with more patients are needed to evaluate the clinical results of surgical technique.

In conclusion, although less advancement of the V-Y flap is achieved at the dorsum of hand fingers, when compared to the dorsum of the big toe, we think that this technique can be preferred due to its good soft tissue coverage, satisfactory cosmetic and functional outcomes and allowing a short time to return to work. The major disadvantage of this technique is the necessity of shortening the distal phalanx in patients with a long nail bed, which was not more than $2 \mathrm{~mm}$.

\section{Declaration of conflicting interests}

The author declared no conflicts of interest with respect to the authorship and/or publication of this article.

\section{Funding}

The author received no financial support for the research and/or authorship of this article.

\section{REFERENCES}

1. Baran R. The nail in the elderly. Clin Dermatol 2011;29:54-60.

2. Freiberg A, Dougherty S. A review of management of ingrown toenails and onychogryphosis. Can Fam Physician 1988:2675-81.

3. Galeone M, Scarfì F, Arunachalam M, Difonzo EM. Ram's horn nails. Clin Exp Dermatol 2012;37:824.

4. Videbaek A. Hereditary onychogryphosis. Ann Eugen 1948;14:139-41.

5. Nath AK, Udayashankar C. Congenital onychogryphosis: Leaning Tower nail. Dermatol Online J 2011;17:9.

6. Baran R, Dawber RPR, Haneke E, Tosti A. Nail plate and soft tissue abnormalities. In: Baran R, Dawber RPR, Haneke E, Tosti A, Bristow I, editors. A Text Atlas of Nail Disorders: Techniques in Investigation and Diagnosis. 3rd ed. London: Martin Dunitz; 2003. p. 100-13.

7. Ko D, Lipner SR. Onychogryphosis: Case report and review of the literature. Skin Appendage Disord 2018;4:326-30.

8. Atik OŞ. Every new technique either conservative or surgical is good? Eklem Hastalik Cerrahisi 2019;30:183-4.

9. Düger T, Yakut E, Öksüz Ç, Yörükan S, Bilgütay BS, Ayhan Ç, et al. Kol, omuz ve el sorunları (disabilities of the arm, shoulder and hand-DASH) anketi Türkçe uyarlamasının güvenirliği ve geçerliği. Turk J Physiother Rehabil 2006;17:99-107.

10. Oka H, Asakage $\mathrm{Y}$, Inagawa $\mathrm{K}$, Moriguchi T, Hamasaki T. Free vascularized nail grafts for onychogryphosis of bilateral thumbnails after burn injury. Burns 2002;28:273-5

11. Kaplan I, Labandter H. Onychogryphosis treated with the CO2 surgical laser. Br J Plast Surg 1976;29:102-3.

12. Dereli T, Özçabalı T, Bostancı Ü, Kapdağlı H. Onikogrifoz sağaitımında total matrisektomi ve fenolizasyon. Turkiye Klinikleri J Dermatol 1995;5:118-20.

13. Atasoy E, Ioakimidis E, Kasdan ML, Kutz JE, Kleinert HE. Reconstruction of the amputated finger tip with a triangular volar flap. A new surgical procedure. J Bone Joint Surg [Am] 1970;52:921-6.

14. Yii NW, Elliot D. Dorsal V-Y advancement flaps in digital reconstruction. J Hand Surg Br 1994;19:91-7.

15. Ozyigit MT, Turkaslan T, Ozsoy Z. Dorsal V-Y advancement flap for amputations of the fingertips. Scand J Plast Reconstr Surg Hand Surg 2007;41:315-9.

16. Zwanenburg RL, Werker PM, McGrouther DA. The anatomy and function of Cleland's ligaments. J Hand Surg Eur Vol 2014;39:482-90.

17. Gürbüz K, Ozan F, Kayali C, Altay T. Total matricectomy and $\mathrm{V}-\mathrm{Y}$ advancement flap technique in the treatment of onychogryphosis. Dermatol Surg 2017;43:583-6.

18. Sabnis A. Morphological Study of Cutaneous Ligaments of Phalanges. Int. J. Morphol 2013;31:606-8.

19. de Berker DA. Phenolic ablation of the nail matrix. Australas J Dermatol 2001;42:59-61. 